SyBENGA, J. (1999): What makes homologous chromosomes find each other in meiosis. A review and hypothesis. Chromosoma 108: 209-219.

TRIPATHI, J. P. M. and S. N. JAIMINI (2002): Floral and reproductive biology of Rohida (Tecomella undulata (Sm.) Seem. Indian Journal of Forestry 25: 341-343.

VenkatasubBan, K. R. (1944): Cytological studies in Bignoniaceae. Annamalai Univ Publ 1,2 and 3: 1-207.
VIR, S., S. K. VERMA and S. K. JINDAL (1994): Relative appearance of important insect pests on select genotypes of Tecomella undulata (Sm.) Seem at Jodhpur. Annals of Arid Zone 33: 161-163.

ZICKLER, D. and N. KLECKNER (1999): Meiotic chromosomes: Integrating structure and function. Annual Review of Genetics 33: 603-754.

\title{
Genotype by Environment Interaction in Pinus sylvestris L. in Southern Sweden
}

\author{
By B. HannRuP ${ }^{\left.1),{ }^{*}\right)}$, G. JAnsson ${ }^{2)}$ and Ö. DANELL ${ }^{3)}$
}

(Received 27 ${ }^{\text {th }}$ April 2007)

\begin{abstract}
To estimate the amount of genotype by environment interaction ( $\mathrm{G} \times \mathrm{E})$ data was obtained within the Swedish breeding program of Pinus sylvestris L. The calculations were based on estimates of G x E expressed by the genetic correlations across trials. In total, 66 progeny trials were included coming from 17 different test series. The number of parents tested per progeny trial was in average 52 . Some parents were tested in several series and in total 812 parents were represented in the study. The results of our study showed that the amount of G x E for growth traits in Pinus sylvestris in southern Sweden was low. The median genetic correlation across trials for height, height increment and diameter were in the range $0.75-0.80$ and the pattern of interaction was largely unpredictable from site differences in site index, latitude, longitude and altitude.
\end{abstract}

Key words: Scots pine, genetic correlation, stability, progeny testing.

\section{Introduction}

Clone and progeny testing in field tests is one of the most important and costly components of a tree breeding program. The objective is to compare the selection candidates under conditions similar to those under which mass-propagated material will be grown. Several considerations have to be made to design an efficient

1) Skogforsk (The Forestry Research Institute of Sweden), Uppsala Science Park, S-751 83 Uppsala, Sweden. E-mail: bjorn.hannrup@skogforsk.se

2) Skogforsk (The Forestry Research Institute of Sweden), Uppsala Science Park, S-751 83 Uppsala, Sweden. E-mail: gunnar.jansson@skogforsk.se

$\left.{ }^{3}\right)$ Reindeer husbandry unit, Swedish University of Agricultural Sciences, P.O. Box 7023, S-750 07 Uppsala, Sweden. E-mail: oje.danell@rene.slu.se

*) Corresponding author: BJÖRN HANNRUP, Skogforsk, Uppsala Science Park, S-751 83 Uppsala, Sweden. Phone +4618188500, fax +4618188600 . E-mail: bjorn.hannrup@skogforsk.se testing, but a key element is to find the optimum number of trials to be used. In Sweden, the testing of Pinus sylvestris L. was designed to identify selection candidates that perform well across sites within seed zones assuming that the genotype by environment interaction ( $\mathrm{G} \times \mathrm{E})$ is low within seed zones. The division of zones was based on the general adaptation pattern of Pinus sylvestris, which in Sweden is characterised by a clinal variation along a latitudinal temperature gradient (LANGLET, 1936; EICHE, 1966). The population differentiation is lower in southern Sweden (JoHNSSON, 1970) as opposed to the stronger effects reported from studies in northern Sweden (ERIKSSON et al., 1980; PERSSON, 1994) where the climate is harsher. As a consequence, larger seed zones have been used in southern than in northern Sweden. Within seed zones the optimum number of trials is highly dependent on the amount of G x E and this optimum number of trials is further explored in an adjacent study (HANNRUP et al., 2007). The large body of Pinus sylvestris progeny tests now being available enables an accurate quantification of the amount of $\mathrm{G} \times \mathrm{E}$ within seed zones of this species in southern Sweden.

An array of statistical methods has been used to quantify the amount of $\mathrm{G} \times \mathrm{E}$ such as traditional analysis of variance, regression methods and multivariate techniques (for review of methods see SKRøPPA, 1984). In Pinus species, such studies have commonly indicated statistical significant interactions, but the interactions have not been sufficiently strong to warrant any further subdivision of breeding populations or seed zones (MATHESON and RAYMOND, 1984; McKeAND et al., 1990; PSWARAYI et al., 1997). Alternatively, genetic correlations across sites have been used to quantify the amount of G x E. FALCONER (1952) introduced the concept of genetic correlations across environments by regarding a character measured in two different environments as two separate traits. As long as the correlation across sites is 
close to unity it can be assumed that the two traits are closely related. BURDON (1977) designated such correlations as type-B genetic correlations and discussed the use of them in forest tree breeding. Using type-B genetic correlations, HAAPANEN (1996) estimated a mean type-B correlation for height of 0.61 from eight series of progeny trials with Pinus sylvestris in Finland. In two extensive studies in Pinus elliottii Engelm. var elliottii HoDGE and White (1992) and DiETERs et al. (1995) reported mean type-B genetic correlations in the interval of $0.60-0.67$ and $0.66-0.88$, respectively, for stem volume in the age interval of 5-15 years. Type-B genetic correlations are commonly based on analysis of variance performed at each site combined with an estimate of the phenotypic correlation of family means across sites. In recent papers dealing with $\mathrm{G} \times \mathrm{E}$ in forest tree breeding, multiple-trait mixed model equations are been used to estimate genetic correlations between traits across sites (e.g. JANSSON et al., 1998). The latter type of analysis benefits from a simultaneous estimate of variances and covariances which makes it more robust against unbalanced data. Another advantage of genetic correlations across sites is the ability to detect rank changes better than many other methods.

The purpose of the present study was to assess G x E for growth traits in Pinus sylvestris in southern Sweden. The estimates of $\mathrm{G} \times \mathrm{E}$ were expressed as genetic correlations across trials. When the correlation for a pair of environments is small, this indicates that parents do not rank the same in both environments. Another aim of the study was to detect factors causing the interaction.

\section{Materials and Methods}

\section{Experimental data}

To estimate the amount of G x E, data was obtained within the Swedish breeding program of Pinus sylvestris. This data refer to the base generation of material for breeding and masspropagation. The parents were phenotypically selected plus-trees, grafted in seed orchards and progeny tested in field trials. The seed crop of a seed orchard was intended for a defined seed zone and the parents were tested within this zone. Typically, five trials were replicated within a series (the trials of one seed orchard composed a series) where three trials were located on the most representative type of site within the seed zone and the remaining two trials on one harsher and one milder site, respectively. For the purpose of the present study, all series in southern Sweden with measurements from at least three replicated trials were selected. In total, there were 66 progeny trials included, coming from 17 different test series. In eight of these series full-sib progenies were used, whereas half-sib progenies were used in nine series (Fig. 1). Among the latter series, six series comprised half-sib progenies generated by collecting openpollinated seeds from mother trees whereas the half-sibs in the remaining three series were generated by mating grafted clones with a pollen mixture of 13 to 18 parents. The average latitudinal and longitudinal differences between trials within series were $0.7^{\circ}$ and $1.2^{\circ}$, respectively, which equal 80 and $68 \mathrm{~km}$, respectively. The corresponding difference between trials for height above sea level was $92 \mathrm{~m}$. The maximum differences in latitude, longitude and altitude between trials within series were $2.9^{\circ}, 3.0^{\circ}$ and $320 \mathrm{~m}$, respectively.

The number of parents tested per trial was in the range of 24 to 92 with an average of 52 parents per trial. Some parents were tested in several series and in total 812 parents were represented in the study. The parents tested within a series were on average selected within a latitudinal and altitudinal range of $2.2^{\circ}$ and $230 \mathrm{~m}$, respectively, with corresponding maximum values of $5.9^{\circ}$ and $375 \mathrm{~m}$, respectively. Among the 66 progeny trials included in the study, 63 trials had a randomised complete block design with non-contiguous single-tree plots. The number of blocks was in most cases ten and each family was mostly represented four times within a block. The remaining three progeny trials had a randomised complete block design (ten blocks) with fourtree plots. In these trials only one tree per four-tree plot was measured. a)

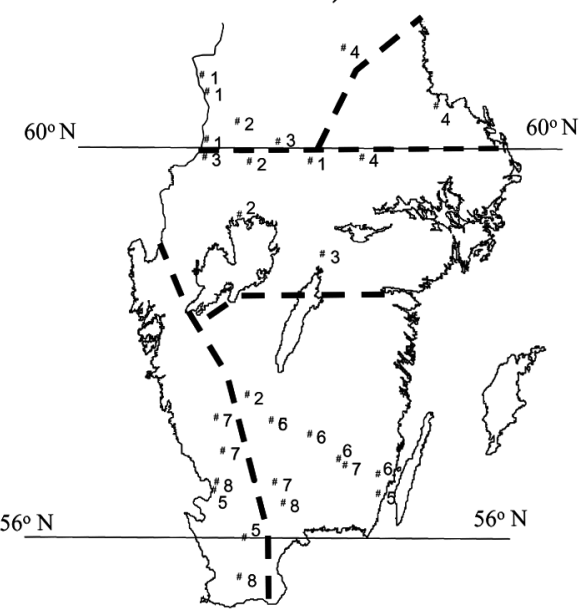

b)

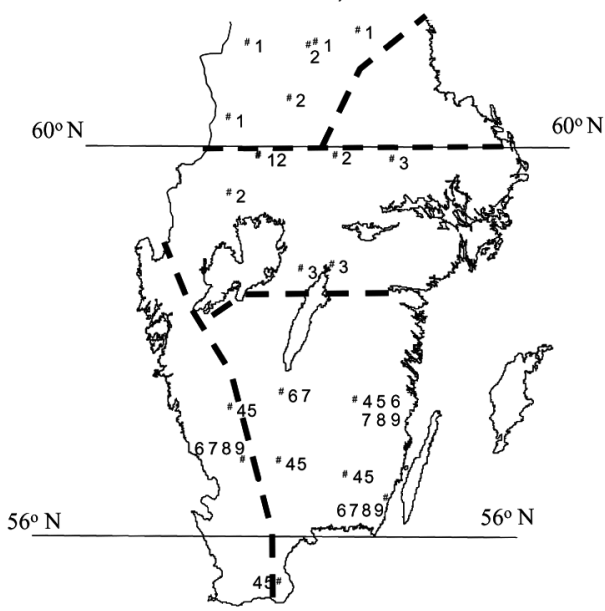

Figure 1. - Location of the 1a) full-sib and 1b) half-sib progeny trials included in the study. Within each figure trials indicated by the same number belong to the same series. Dashed lines indicate the delimitation of seed zones. 
The characters analysed in this study were height, height increment, i.e. the difference between two subsequent height measurements, and breast height diameter. Height was measured twice in 57 of the trials and for three trials only the height increment data was available. Six trials were measured once for height. Breast height diameter was measured in 52 of the 66 trials and only once in the trials where it was measured. The age at measurement (number of growing seasons in the field) varied among the trials, but most trials were measured for height at age five and ten and for breast height diameter at age ten. The oldest age at measurement was 17 years. The number of measured progenies per parent within a trial varied between trials and characters, but was on average 28 for height and height increment and 20 for breast height diameter. The mean height of the trials was in the range of 0.8 to $12.0 \mathrm{~m} \mathrm{(5}$ and 16 years in the field, respectively) with an overall average of $3.2 \mathrm{~m}$.

\section{Statistical analyses}

The statistical analyses were based on multiple-trait mixed model equations (MME) and variances and covariances were estimated with the Average Information algorithm (GILMOUR et al., 1995) for restricted maximum likelihood (REML) estimates as performed in the ASReml software (GILMOUR et al., 1999). The statistical analyses were made in two steps; (i) univariate analysis where variance components for each character within each trial were estimated, (ii) two-site analysis where variances and covariances between characters across trials were simultaneously estimated between pairs of trials within series of progeny trials. The variables measured in the progeny trials within a series were considered as different characters in the analyses, e.g., measurements of height in two trials were considered as measurements of two different characters. Estimated (co)variances between characters across trials were only made for combinations of trials where the characters had been measured at the same or similar ages. The statistical model used in the univariate analyses of the fullsib trials was:

$$
\mathbf{y}_{1}=\mathbf{X}_{1} \mathbf{b}_{1}+\mathbf{Z}_{1} \mathbf{p}_{1}+\mathbf{W}_{1} \mathbf{f}_{1}+\mathbf{e}_{1} \text { and }
$$

the following two-site model, which is an extension of [1], was used in the analyses of the full-sib trials:

$$
\left[\begin{array}{l}
\mathbf{y}_{1} \\
\mathbf{y}_{2}
\end{array}\right]=\left[\begin{array}{cc}
\mathbf{X}_{1} & \mathbf{0} \\
\mathbf{0} & \mathbf{X}_{2}
\end{array}\right]\left[\begin{array}{l}
\mathbf{b}_{1} \\
\mathbf{b}_{2}
\end{array}\right]+\left[\begin{array}{cc}
\mathbf{Z}_{1} & \mathbf{0} \\
\mathbf{0} & \mathbf{Z}_{2}
\end{array}\right]\left[\begin{array}{l}
\mathbf{p}_{1} \\
\mathbf{p}_{2}
\end{array}\right]+\left[\begin{array}{cc}
\mathbf{W}_{1} & \mathbf{0} \\
\mathbf{0} & \mathbf{W}_{2}
\end{array}\right]\left[\begin{array}{l}
\mathbf{f}_{1} \\
\mathbf{f}_{2}
\end{array}\right]+\left[\begin{array}{l}
\mathbf{e}_{1} \\
\mathbf{e}_{2}
\end{array}\right],
$$

where $\mathbf{y}_{1}$ and $\mathbf{y}_{2}$ are observation vectors for the two sites, $\mathbf{X}_{1}$ and $\mathbf{X}_{2}$ are design matrices for fixed block effects, $\mathbf{b}_{1}$ and $\mathbf{b}_{2}$ are vectors of fixed block effects, $\mathbf{Z}_{1}$ and $\mathbf{Z}_{2}$ are design matrices for random parent effects, $\mathbf{p}_{1}$ and $\mathbf{p}_{2}$ are vectors of random parent effects, $\mathbf{W}_{1}$ and $\mathbf{W}_{2}$ are design matrices for random family effects, $\mathbf{f}_{1}$ and $\mathbf{f}_{2}$ are vectors of random family effects and $\mathbf{e}_{1}$ and $\mathbf{e}_{2}$ are vectors of random residuals.

The random factors were assumed to be normally distributed with expectation zero and, consequently,

$$
E\left[\begin{array}{l}
\mathbf{y}_{1} \\
\mathbf{y}_{2}
\end{array}\right]=\left[\begin{array}{l}
\mathbf{X}_{1} \mathbf{b}_{1} \\
\mathbf{X}_{2} \mathbf{b}_{2}
\end{array}\right]
$$

Furthermore, the (co)variances of the random effects were assumed to be

$$
\operatorname{Var}\left[\begin{array}{l}
\mathbf{p} \\
\mathbf{f} \\
\mathbf{e}
\end{array}\right]=\left[\begin{array}{ccc}
\mathbf{G} \otimes \mathbf{I}_{1} & \mathbf{0} & \mathbf{0} \\
\mathbf{0} & \mathbf{D} \otimes \mathbf{I}_{2} & \mathbf{0} \\
\mathbf{0} & \mathbf{0} & \mathbf{R}
\end{array}\right]
$$

where $\mathbf{p}^{\prime}=\left(\mathbf{p}_{1}^{\prime}, \mathbf{p}_{2}^{\prime}\right), \mathbf{f}^{\prime}=\left(\mathbf{f}_{1}^{\prime}, \mathbf{f}_{2}^{\prime}\right)$ and $\mathbf{e}^{\prime}=\left(\mathbf{e}_{1}^{\prime}, \mathbf{e}_{2}{ }_{2}\right)$. G is the matrix with the parental variances and covariances, $\mathbf{D}$ is the matrix with the family variances and covariances and $\mathbf{I}_{1}$ and $\mathbf{I}_{2}$ are identity matrices with dimensions equal to the number of parents and families, respectively. $\mathbf{R}$ is the error covariance matrix equal to $\Sigma_{\oplus} \mathbf{R}_{i}$ where $\mathbf{R}_{i}$ is a diagonal error matrix for the individuals in trait $i$. The parents were assumed unrelated and it was further assumed that no maternal effects were present at the ages studied.

For the analyses of the half-sib trials the models [1] and [2] were used with the family effects excluded. The expectations and assumptions made for these less complex models were apart from the family effects the same as for [1] and [2].

The additive $\hat{\sigma}_{A}^{2}$ variance components were estimated as

$\hat{\sigma}_{A}^{2}=4 \hat{\sigma}_{p}^{2}$

where $\hat{\sigma}_{p}^{2}$ is the parental variance. The phenotypic variance was estimated as

$$
\begin{aligned}
& \hat{\sigma}_{p}^{2}=\hat{\sigma}_{p}^{2}+\hat{\sigma}_{e}^{2} \text { or } \\
& \hat{\sigma}_{p}^{2}=2 \hat{\sigma}_{p}^{2}+\hat{\sigma}_{f}^{2}+\hat{\sigma}_{e}^{2}
\end{aligned}
$$

in the half-sib or full-sib trials, respectively, where $\hat{\sigma}_{e}^{2}$ is the residual variance.

The additive genetic covariance, $\hat{\sigma}_{A_{1} A_{2}}$, where in both cases estimated as four times the parental covariance. The estimates of individual tree heritabilities $\left(\hat{h}^{2}\right)$ and additive genetic correlations $\left(\hat{r}_{A}\right)$ across trials were computed as

$$
\begin{aligned}
& \hat{h}^{2}=\frac{\hat{\sigma}_{A}^{2}}{\hat{\sigma}_{P}^{2}} \text { and } \\
& \hat{r}_{A}=\frac{\hat{\sigma}_{A_{1} A_{2}}}{\hat{\sigma}_{A_{1}} \hat{\sigma}_{A_{2}}} .
\end{aligned}
$$

Genetic correlations were computed for all possible pairwise combinations of trials within series. In those few cases where the $\mathbf{G}$ matrix was not positive definite the same analysis was repeated but with a constraint included in the ASReml software. This constraint reduced the parental covariance until the G-matrix was just positive definite (GILMOUR et al., 1999). Estimates of the standard errors of the genetic parameters were obtained with the ASReml software using a Taylor series approximation (GILMOUR et al., 1999).

Multiple linear regressions were performed to determine if it was possible to predict the genetic correlations across sites from the site- and locality variables. The following model was used

$$
r_{i j}=b_{0}+b_{1} x_{i j 1}+\ldots+b_{n} x_{i j n}+e_{i j}
$$

where $r_{i j}$ is the genetic correlation between trial $i$ and $j$, $x_{i j}$ are the differences in site- and locality variables 
between trial $i$ and $j, b$ are the regression coefficients and $e$ is the random residual. The following variables were tested latitude, longitude, altitude and site index.

\section{Results}

\section{Genetic parameters}

Mean values across trials and ages of the heritability and additive coefficient of genetic variation for the studied characters are presented in Table 1. The heritability means were $0.21,0.26$ and 0.17 for height, height increment and breast height diameter, respectively. The mean heritability for height and height increment of the series with full-sib progenies were similar as for the series of half-sib progenies (data not shown).

Table 1. - Mean values across trials and ages of heritability with standard deviations in parenthesis, additive coefficient of genetic variation $\left(C V_{\mathrm{A}}\right)$ and number of estimates $(n)$ for height (ht), height increment (ht_inc) and breast height diameter (dbh).

\begin{tabular}{lccc}
\hline Trait & $h^{2}$ (s.d.) & $C V_{\mathrm{A}}(\%)$ & $n$ \\
\hline ht & $0.21(0.12)$ & 7.9 & 120 \\
ht_inc & $0.26(0.11)$ & 9.8 & 60 \\
dbh & $0.17(0.09)$ & 10.6 & 52 \\
\hline
\end{tabular}

The median genetic correlation across trials for all characters were in the range $0.75-0.80$ for the pooled data (Table 2); corresponding mean values were slightly lower. The estimates of the genetic correlation from the half-sib and full-sib material were similar for height and height increment, whereas for breast height diameter, the full-sib material yielded a lower estimate of the genetic correlation. Frequency distributions of the genetic correlation across trials for height and breast height diameter are shown in Fig. 2. There was a tendency of the genetic correlations to be more clustered for height whereas the correlations for breast height diameter were distributed over a wider range with a pronounced peak in the highest class $\left(r_{\mathrm{A}}=0.90-1.0\right)$.

Height was measured in the age interval of 4-17 years. Within this interval there was no age trend for the estimates of the genetic correlation across trials (Fig. 3). Breast height diameter was measured in a more narrow age interval and within this interval no consistent age trend could be observed (Fig. 3).

The estimated genetic correlations across sites dependent on the difference in site index, latitude, longitude and altitude between the trials were unpredictable. The multiple regression with these site and locality variables in the model did never explain more than $17 \%$ of

Table 2. - Median and mean values of the additive genetic correlation $\left(r_{\mathrm{A}}\right)$ across trials estimated from half-sib progeny trials, full-sib progeny trials and pooled for height (ht), height increment (ht_inc) and breast height diameter (dbh).

\begin{tabular}{|c|c|c|c|c|c|c|c|c|c|}
\hline \multirow[b]{2}{*}{ Trait } & \multicolumn{3}{|c|}{$r_{\mathrm{A}}$ median } & \multicolumn{5}{|c|}{$r_{\mathrm{A}}$ mcan } & \multirow[b]{2}{*}{$n$} \\
\hline & Half-sib & Full-sib & Pooled & Half-sib & $n$ & Full-sib & $n$ & Pooled & \\
\hline $\mathrm{Ht}$ & 0.79 & 0.82 & 0.80 & 0.77 & 114 & 0.78 & 66 & 0.77 & 180 \\
\hline ht__inc & 0.78 & 0.77 & 0.77 & 0.76 & 53 & 0.74 & 33 & 0.75 & 86 \\
\hline Dbh & 0.80 & 0.59 & 0.75 & 0.69 & 53 & 0.50 & 22 & 0.64 & 75 \\
\hline
\end{tabular}

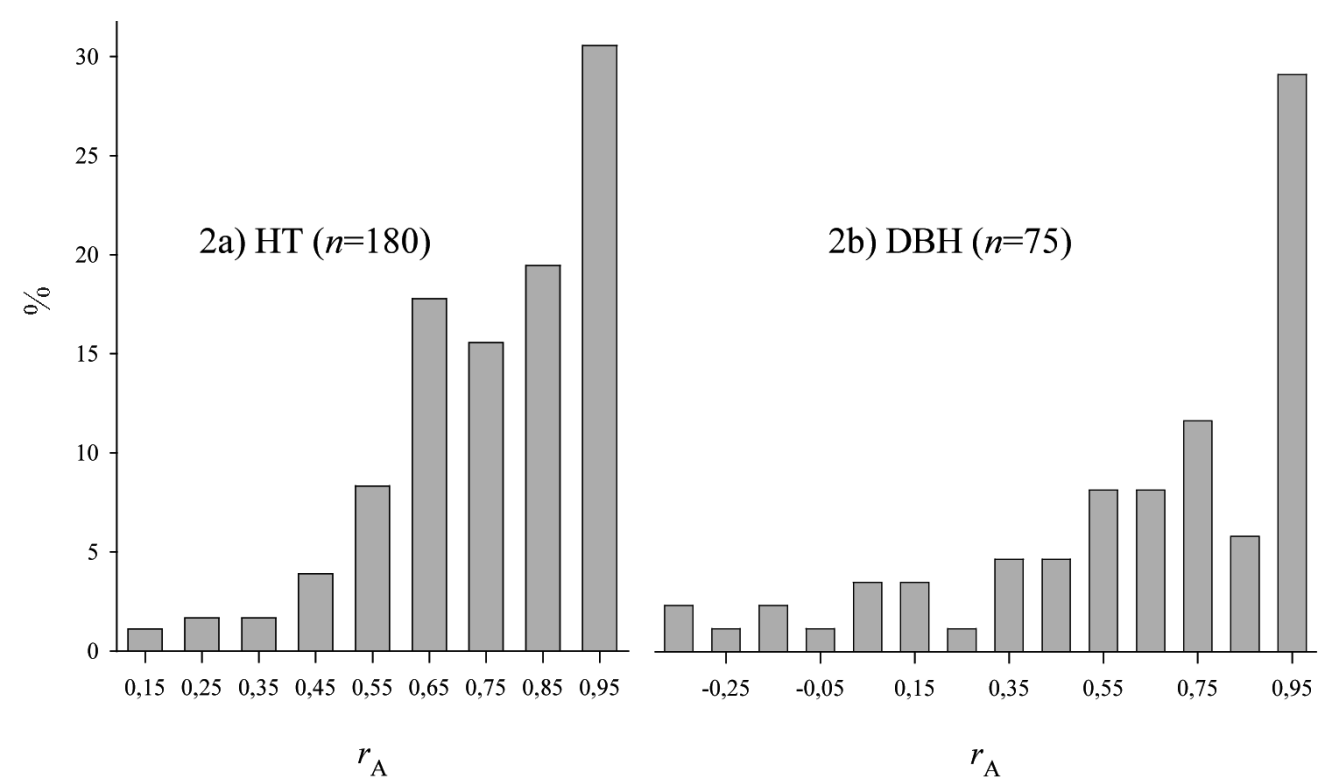

Figure 2. - Frequency distribution of the additive genetic correlation across trials for 2a) height and $2 \mathrm{~b}$ ) breast height diameter. The $\mathrm{y}$-axis indicates the percentage of the total number of observations for each trait that falls in each class. Observe that the range of the $\mathrm{x}$-axis is different for the traits. 


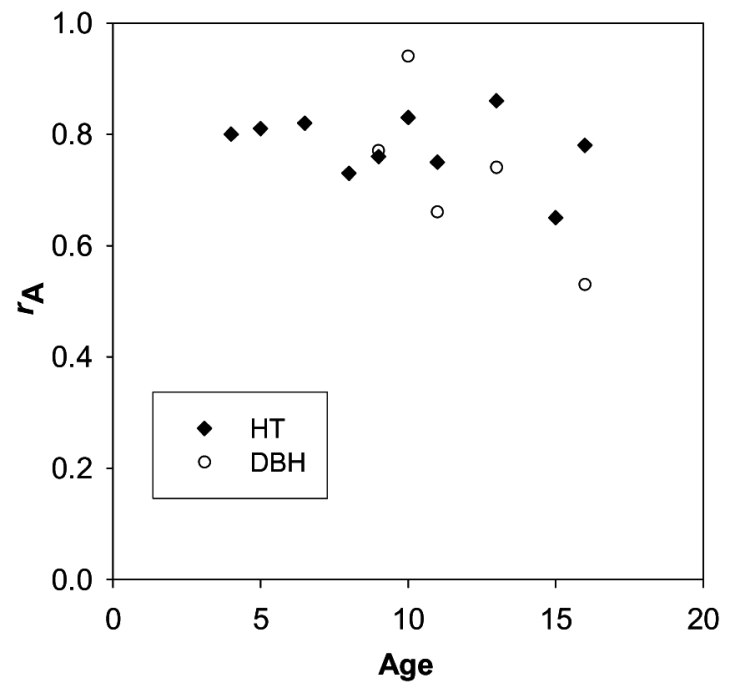

Figure 3. - Plot of the median additive genetic correlation across trials estimated at various ages (number of growing seasons in the field) for height (HT) and breast height diameter (DBH).

the total variation for the characters studied (data not shown).

\section{Discussion}

\section{Heritabilities and additive coefficients of genetic variation}

The mean heritability and additive coefficient of genetic variation $\left(C V_{\mathrm{A}}\right)$ for height and breast height diameter (Table 1) are similar as corresponding median values reported from a compilation of studies across species (CoRNELIUS, 1994). The mean heritability for height was the same from the full-sib as from the halfsib material indicating that the sample sizes of these two groups were sufficient for the means to converge towards a stable value.

Height increment had a higher heritability and $C V_{\mathrm{A}}$ than height (Table 1). The difference among the two characters may be caused by establishment effects which increase the environmental effect. Height increment is less affected by random establishment effects occurring in the years following planting as the earliest height measurement was made after four growing seasons in the field.

\section{Genetic correlations}

The genetic correlations across trials within series were used to quantify the amount of $\mathrm{G} \times \mathrm{E}$ within seed zones. The median values were not below 0.75 for any trait (Table 2), indicating that the $\mathrm{G} \times \mathrm{E}$ was in general low in this material. The result in our study show a lower amount of $\mathrm{G} \times \mathrm{E}$ as compared to earlier studies in Pinus sylvestris (LINDGREN, 1984; GullBerg and VEGERFORS, 1987) using ANOVA-based methods with limited materials. Using data from the Finnish Pinus sylvestris breeding program, HAAPANEN (1996) estimated a mean type-B genetic correlation across sites of 0.61 for height at age 10 . This estimate was lower than corre- sponding estimate in the present study, probably due to the more northerly location of the Finnish trials. At higher latitudes the climatic gradient is steeper and therefore the trials may have comprised a higher environmental variation. In a study of Picea abies (L.) Karst. in western Denmark and southern Sweden, the median genotypic correlation across sites was 0.54 for height growth at age 11-14 years (KARLSSON et al., 2001). Damage by spring frost was assumed to be the main course of $\mathrm{G} \times \mathrm{E}$.

It should be noted that the progeny trials used in the present study were part of the operational breeding programme and they were not laid out with the primary purpose to study $\mathrm{G} \times \mathrm{E}$. The drawback of this condition was a rather limited range of the environments studied. The maximum latitudinal difference among trials within a series were $2.9^{\circ}$. However, within this range there was no tendency for the genetic correlation to decrease with increasing difference in latitude of the trials as shown from the multiple regression of site and localityvariables. This was confirmed by a closer examination of the series with maximum differences in latitude. In series 2 (Fig. 1a) there was no difference between the correlations with the most southern trial and the correlations between the other three trials. Furthermore, no east-west interaction pattern was detected. In the most appropriate series to study this, series 5 (Fig. 1a), there was a high correlation for height $\left(r_{\mathrm{A}}=0.86\right)$ between the trial located in the region of high precipitation in western Sweden and the trial located in the region of frequent early summer drought on the east coast. Neither did HAAPANEN (1996) find any predictable pattern in family-by-trial interaction. In his study none of the studied environmental variables explained a significant portion of the across site genetic correlation.

The estimates of the genetic correlation were not normally distributed (Fig. 2) and we consider the median values as more appropriate than the arithmetic mean. However, the differences between median and mean values were small except for breast height diameter, which also had the genetic correlations distributed over a wider range. The wider distribution of the genetic correlation for breast height diameter is best explained by the lower precision in the estimates of the genetic correlation as a consequence of the lower sample size and heritability for this character. The six negative genetic correlations for breast height diameter were all found in pairs of trials, where either of the heritabilites in the two trials were not significantly different from zero $(\mathrm{p}>0.05)$.

For height, no age trend was observed for the genetic correlation across trials (Fig. 3). This indicates that, regarding $\mathrm{G} \times \mathrm{E}$, it is indifferent at what age the selection is carried out. Studying a similar age interval in Pinus elliottii, HodGe and WHITE (1992) reported no age trend for the type-B genetic correlation across trials of stem volume. However, contrary to this, a study in the same species by DIETERs et al. (1995) indicated a corresponding increasing genetic correlation with age for stem volume. Breast height diameter did not show a consistent age trend of the genetic correlation across 
trial (Fig. 3) and no strong conclusions may be drawn for this character. It is suggested that the irregular pattern observed is an effect of sampling as the number of observation for each age class was low and could be too dependant on a particular series.

In conclusion data used in our study showed that there is little genotype by environment interaction for growth traits in Pinus sylvestris in southern Sweden as indicated by median genetic correlations across trials above 0.75 for height, height increment and diameter. Our results also showed that the pattern of genotype by environment was largely unpredictable.

\section{Acknowledgements}

The personnel at Brunsberg Field station and Ekebo Research station skilfully established, maintained and measured the trials used.

\section{Reference list}

BURDon, R. D. (1977): Genetic correlation as a concept for studying genotype-environment interaction in forest tree breeding. Silvae Genet. 26: 168-175.

CoRnelius, J. (1994): Heritabilities and additive genetic coefficient of variation in forest trees. Can. J. For. Res. 24: 372-379.

Dieters, M. J., T. L. White and G. R. Hodge (1995): Genetic parameter estimates for volume from full-sib tests of slash pine (Pinus elliottii). Can. J. For. Res. 25: 1397-1408.

EICHE, V. (1966): Cold damage and plant mortality in experimental provenance plantations in northern Sweden. Studia For. Suecia. 36: 1-218.

Eriksson, G., S. Andersson, V. Eiche, J. Ifver and A. Persson (1980): Severity index and transfer effects on survival and volume prodution of Pinus sylvestris in northern Sweden. Studia For. Suecia. 156: 1-32.

FALCONER, D. S. (1952): The problem of environment and selection. Am. Nat. 86: 293-298.

Gilmour, A. R., R. THOMPson and B. R. Cullis (1995): Average Information REML, an efficient algorithm for variance parameter estimation in linear mixed models. Biometrics 52: 1440-1450.

Gilmour, A. R., B. R. Cullis, S. J. Welham and R. ThompSON (1999): ASREML Reference Manual. Orange, Australia. $210 \mathrm{pp}$.

GullBerg, U. and B. Vegerfors (1987): Genotype-Environment Interaction in Swedish Material of Pinus sylvestris. Scand. J. For. Res. 2: 417-432.

HAAPANEN, M. (1996): Impact of family-by-trial interaction on the utility of progeny testing methods for Scots Pine. Silvae Genet. 45: 130-135.
HANNRUP, B., G. JANsson and Ö. DANELl (2007): Comparing gain and optimum test size from progeny testing and phenotypic selection in Pinus sylvestris. Can. J. For. Res. 37: 1227-1235.

Hodge, G. R. and T. L. White (1992): Genetic parameter estimates for growth traits at different ages in Slash Pine and some implications for breeding. Silvae Genet. 41: 252-262.

Jansson, G., Ö. DAnell and L.-G. Stener (1998): Correspondence between single-tree and multiple-tree plot genetic tests for production traits in Pinus sylvestris. Can. J. For. Res. 28: 450-458.

Johnsson, H. (1970): Provenance trials with Scots pine in Southern Sweden. Inst. For. Improv. Yearbook 1970: 87-122. (In Swedish)

Karlsson, B., H. Wellendorf, H. Roulund and M. WeRNER (2001): Genotype $\mathrm{x}$ trial interaction and stability across sites in 11 combined provenance and clone experiments with Picea abies in Denmark and Sweden. Can. J. For. Res. 31: 1826-1836.

LANGLET, O. (1936): Studier över tallens fysiologiska variabilitet och dess samband med klimatet. Ett bidrag till kännedom om tallens ekotyper (studien über die physiologische Variabilität der Kiefer und deren Zusammenhang mit dem Klima. Beiträge zur Kenntnis der Ökotypen von Pinus silvestris L.). Medd. Statens Skogsförsöksanst. 4: 219-470. (Summary in U.S. Forest Service translation No. 239, 1937.

LINDGREN, D. (1984): Prediction and optimization of genetic gain with regard to genotype $\mathrm{x}$ environment interactions. In: Proceedings from a conference on genotype $\mathrm{x}$ environment interaction, 23-27 August 1982, Uppsala, Sweden. Studia Forestalia Suecica No. 166, pp. 15-24.

Matheson, A. C. and C. A. RAYMOND (1984): The impact of genotype $\mathrm{x}$ environment interactions on Australian Pinus radiata breeding programs. Austr. For. Res. 14: 11-25.

McKeand, S. E., B. Li, A. V. Hatcher and R. J. Weir (1990): Stability parameter estimates for loblolly pine families growing in different regions in the southeastern United States. For. Sci. 36: 10-17.

Persson, B. (1994): Effects of climate and provenance transfer on survival, production and stem quality of Scots pine (Pinus sylvestris L.) in northern Sweden. Swedish Univ. Agric. Sci. Dept For. Yield Res. Report 37, 42pp. Doctoral thesis.

Pswarayi, I. Z., R. D. BARNes, J. S. Birks and P. J. KANOWSKI (1997): Genotype-environment interaction in a population of Pinus elliottii Engelm. var. elliottii. Silvae Genet. 46: 35-40.

SKRøPPA, T. (1984): A critical evaluation of methods available to estimate the genotype $\mathrm{x}$ environment interaction. In Proceedings from a conference on genotype $\mathrm{x}$ environment interaction, 23-27 August 1982, Uppsala, Sweden. Studia For. Suecia 166: 3-14. 